\title{
Review of the pharmacological and bariatric surgery for diabesity
}

Abbreviations: T2DM, type 2 diabetes; PBF, percentage body fat; NEFA, nonesterified fatty acid; SIGN, scottish intercollegiate guidelines network; ADA, American diabetes association; AGB, adjustable gastric banding; SG, sleeve gastrectomy; RYGB, rouxen-Y gastric bypass

\section{Introduction}

The intrinsic association between obesity and Type 2 diabetes (T2DM) is well recognised, to the extent that the term Diabesity was coined by Dr Ethan Sims. ${ }^{1}$ The definition of obesity according to the World Health Organization is "a condition in which percentage body fat $(\mathrm{PBF})$ is increased to an extent in which health and well-being are impaired, ${ }^{2}$ " as is the case in T2DM where obesity compounds disease progression. ${ }^{3,4}$ Obesity contributes to insulin resistance, ${ }^{5}$ and as such addressing obesity is a vital aspect in the management of T2DM. ${ }^{6}$ Moderate and maintained weight loss has been demonstrated to be effective in lowering glycaemic levels in obese people with T2DM as well as reducing the need for oral hypoglycaemic medications. ${ }^{7} \mathrm{~T} 2 \mathrm{DM}$ guidelines recommend lifestyle interventions as first line management for obesity yet despite the evidence that lifestyle modifications can elicit $5-10 \%$ weight $\operatorname{loss}^{8}$ and have clinically significant benefits in the management of T2DM many patients are unable to accomplish or sustain this in the long term. ${ }^{6}$ This review will explore the evidence for pharmacological and surgical management for obesity in T2DM.

\section{Pathophysiology of obesity in T2DM}

Modulation of metabolism occurs with the release of nonesterified fatty acid (NEFA) as well as other substances, including proinflammatory substances, cytokines, leptin and glycerol from adipose tissue. ${ }^{5,9}$ The release of NEFA is a major influence of insulin insensitivity and insulin resistance and may explain the connection between $\beta$ cell dysfunction and insulin resistance. ${ }^{9}$ Increased secretion of NEFA from adipose tissue is seen in obese individuals and T2DM. Development of insulin resistance commences with increased NEFA levels. However, with a reduction of NEFA plasma levels such as through the use an anti-lipolytic agent, homeostasis of glucose and peripheral insulin uptake are improved. ${ }^{5}$ This demonstrates the importance of addressing obesity as part of the management plan to improve glycaemic control and reduce the myriad of obesity associated health complications.

Weight loss of $5-10 \%$ in obese people with T2DM can improve glycaemic control, cholesterol and blood pressure, ${ }^{8}$ and is recommended by the Scottish Intercollegiate Guidelines Network (SIGN) for obesity management. ${ }^{10}$ These guidelines go further in recommending weight loss of $15-20 \%$ in people with a BMI $>35 \mathrm{~kg} /$ $\mathrm{m}^{2}$. Anti-obesity drugs have been demonstrated to elicit a weight reduction of $7-10 \%$ over $2-4$ years, ${ }^{11}$ which may address some of the adversities of Diabesity but yet falls short of the weight loss recommendations by SIGN. ${ }^{10}$ This raises the question, Is anti-obesity medication effective as a stand-alone intervention and should other modalities be considered such as bariatric surgery?. ${ }^{12}$

\author{
Volume I Issue I - 2017 \\ Emmeline de Gruchy, Vinay S Eligar
University Hospital of Wales, UK
}

Correspondence: Vinay S Eligar, Consultant in Diabetes and Endocrinology, University Hospital of Wales, Cardiff, UK, Email eligarvs@gmail.com

Received: March 16, 2017| Published: April 12, 2017

\section{Pharmacological management of obesity in T2DM}

Pharmacological management of hyperglycaemia in T2DM is of paramount importance yet consideration should be given to those medications that are weight neutral or have potential to augment weight loss, see Table 1 for classes of anti-diabetic drugs in these categories and associated benefits and side effects. As the table demonstrates pharmacotherapy can have a significant clinical impact on weight loss and glycaemic control yet this has to be weighed against the adverse effects experienced by each individual. It must also be noted that lifestyle intervention (diet and physical activity) should be recommended as an essential along with the pharmacological management strategy. ${ }^{7}$

A systematic review by Yanovski et al. ${ }^{13}$ reported that lifestyle intervention combined with either Orlistat, Phentermine/topiramate or Lorcaserin increases the prospect of patients to realise a $>5 \%$ weight reduction in 12 months. However it must be recognised that the availability of these licensed drugs varies globally. The American Diabetes Association (ADA) and SIGN recommend ceasing antiobesity medications at 3 months or earlier if any complications arise. If the weight reduction is $<5 \%$ from baseline then consider alternate medications. ${ }^{7,10}$

The timeframe used by clinical trials varies, however most report results at 12 months, whereas in the 'real world' setting these antiobesity drugs should have been ceased at 3 months if following the ADA and SIGN recommendations. ${ }^{14,15}$ Thus clinical trial data may often not be translatable to the 'real world' setting as recognised by Dunkley, et al. ${ }^{16}$ It may be prudent to continue them if a trend of weight loss is recognised without adverse events for slightly longer (6-12 months) for pragmatic reasons.

Whilst some drugs are specifically licensed and targeted at weight loss there are also other classes of drugs that can elicit weight loss despite their primary usage or original design being for a different outcome. Table 2 highlights the efficacy of the most common drugs prescribed for weight loss as an adjunct therapy for T2DM. A new treatment being explored is the use of Botulinum Toxin, the premise being that Botox injections into the stomach wall inhibit vagus nerve afferents thus interrupting the brain-gut axis communication pathway 
resulting in weight loss. ${ }^{17}$ Phase two of clinical trial is currently being conducted to assess the efficacy and safety of Botulinum Toxin as a weight loss intervention; this may offer a new innovative treatment for obesity in T2DM.

Table I Weight loss with Anti-diabetic drugs

\begin{tabular}{|c|c|c|c|c|}
\hline Drug class \& medication & $\begin{array}{l}\text { Potential effect on } \\
\text { weight }\end{array}$ & $\begin{array}{l}\text { Reduction in } \\
\text { A1c }\end{array}$ & Side effects & Reference \\
\hline Biguanide (Metformin) & $2-3 \mathrm{~kg}$ weight loss & $1.5-2 \%$ & Lactic acidosis, gastrointestinal & $\begin{array}{l}\text { (Goswani, et al., } \\
\text { 2014) }\end{array}$ \\
\hline $\begin{array}{l}\text { Sodium-glucose co transporter } 2 \\
\text { inhibitors (SGLT2)(Empagliflozin } \\
\text { Canagliflozin, Dapagliflozin) }\end{array}$ & $2-3 \mathrm{~kg}$ weight loss & $0.6-0.9 \%$ & $\begin{array}{l}\text { Urinary tract infection, genital } \\
\text { mycotic infection, increase in } \\
\text { potassium, creatinine and low } \\
\text { density lipoproteins cholesterol }\end{array}$ & $\begin{array}{l}\text { (Goswani, et al., } \\
\text { 2014; Abdul- } \\
\text { Ghani, et al., } \\
\text { 2016) }\end{array}$ \\
\hline $\begin{array}{l}\text { Glucagon-like peptide } 1 \text { agonists } \\
\text { (Exenatide, Liraglutide, Dulaglutide) }\end{array}$ & $2.87-3.84 \mathrm{~kg}$ weight loss & $0.9-1 \%$ & $\begin{array}{l}\text { Medullary thyroid cancer, acute } \\
\text { pancreatitis, gastrointestinal }\end{array}$ & $\begin{array}{l}\text { (Goswani, et al., } \\
\text { 2014) Umpierrez } \\
\text { GE et al } 2016\end{array}$ \\
\hline Amylin analogues (Pramlintide) & $2.57 \mathrm{~kg}$ weight loss & $0.3-0.4 \%$ & Gastrointestinal & $\begin{array}{l}\text { (Goswani, et al., } \\
\text { 2014) }\end{array}$ \\
\hline
\end{tabular}

Table 2 Pharmaceuticals for weight loss

Mechanism of action
Side effects
Proportion

of subjects

achieving

$>5 \%$ weight

loss
Inhibits pancreatic and gastric lipase thus reducing absorption of energy dense fat (National Health and Medical Research Council, 2013)
Selective Serotonin receptor agonist (Lorcaserin)

Sympathomimetic amine anorectic/antiepileptic combination Phentermine

plus

Toprimate

Opioid antagonist/ aminoketone antidepressant combination (Naltrexone / bupropion)

Acylated human glucagonlike peptide 1 receptor agonist (Liraglutide)
Selective stimulation of 5HT2C which regulates appetite and promotes satiety (Van Gaal \& Scheen, 2015)
Gastrointestinal side effects such as: fatty faecal incontinence, steatorrhea, urgency of bowel movements

Fatigue, dizziness, nausea and headaches (Yanovski \& Yanovski, 2014)

\section{Weight loss}

\section{$2.6-3.7 \mathrm{~kg}$ weight loss (National Health and} Medical Research Council, 2013). 3\% weight loss (Yanovski \&

Yanovski, 2014)

$3 \%$ weight loss

Yanovski \& Yanovski, $\quad 37-47 \%$

2014) 3kg (American, (Yanovski

Diabetes Association, 2016)

Insomnia, irritability (Yanovski \& Yanovski,

$9 \%$ weight loss

$67-70 \%$ Targets hypothalamus to Stimulate
adrenal glands to release noradrenaline which regulates appetite and promotes satiety (Van Gaal \& Scheen, 2015)

(Yanovski \& Yanovski, 2014)
(Yanovsk

\& Yanovski,

2014)

Antiepileptic drug works on multiple cellular levels- unknown how this reduces weight (Van Gaal \& Scheen, 2015)

Influences the hypothalamic melanocortin system and food cravings and moods through the brain reward systems (Billes, et al., 2014)
Constipation, nausea, vomiting (American Diabetes Association, 2016)

$\begin{array}{ll}2-4.1 \mathrm{~kg} \text { (American } & 36-57 \% \\ \text { Diabetes Association, } & \text { (American } \\ 2016) & \text { Diabetes } \\ & \text { Association, } \\ & 2016)\end{array}$

$51-73 \%$

Hypoglycaemia, headaches, diarrhoea (American Diabetes

Association, 2016) 5.8-5.9kg (American Diabetes Association, 2016)
(American

Diabetes

Association, 2016) 


\section{Surgical intervention for obesity in T2DM}

Bariatric surgery is also called gastrointestinal surgery for obesity. Surgery changes the digestive process which elicits weight loss through reduction of nutrient absorption and thus lessens calorie intake. ${ }^{18}$ The most common types of bariatric surgery are Adjustable Gastric Banding (AGB), Sleeve Gastrectomy (SG) and Roux-en-Y Gastric Bypass (RYGB). RYGB is currently considered the gold standard of weight loss surgery. ${ }^{18}$ The mechanism of weight loss and differences in outcomes of these procedures can be seen in Table 3.

Indications for bariatric surgery are people with a BMI of $40 \mathrm{~kg} /$ $\mathrm{m}^{2}$ or greater, or those with a BMI of $35 \mathrm{~kg} / \mathrm{m}^{2}$ or greater with co morbidities, such as T2DM (NICE, 2014). The NICE guidelines ${ }^{19}$ advice that people diagnosed with T2DM in the past 10 years should receive expedited referrals without the need of having tried lifestyle management interventions first, due to improvements in quality of life and reduced risk of mortality that bariatric surgery can offer. Explored the effects of bariatric surgery during different stages of T2DM progression..$^{20}$ The results demonstrated that bariatric surgery during early onset of T2DM elicited highest rates of T2DM remission and reduced micro and macrovascular complications, whereas bariatric surgery on people with T2DM with existing micro or macrovascular complications produced no improvements in life expectancy or regression of microvascular complications. ${ }^{20}$ Bariatric surgery is considered the most sustainable and effective management for obesity (class III). ${ }^{21}$ Several studies purport that weight loss through bariatric surgery is cost-effective compared to nonsurgical management. ${ }^{11,22,23}$

Following RYGB surgery NEFA levels initially increase with fat deployment through rapid weight loss, levels of NEFA normalise as weight loss plateaus Dirksen, et al. ${ }^{24} \mathrm{SG}$ and RYGB affect pancreatic $\beta$ cell function, NEFA levels and insulin sensitivity thus enhancing glucose metabolism Thomas, et al..$^{25}$

A meta-analysis by Buchwald, et al. ${ }^{26}$ demonstrated remission of T2DM of $57 \%$ for gastric banding and $80 \%$ for gastric bypass. These results correlate with a large scale trial of bariatric surgery in Sweden (the SOS project) that showed $72 \%$ remission of T2DM post-surgery at 2 years. ${ }^{11}$ This evidence supports the use of bariatric surgery for management of obesity in T2DM.

Table 3 Common Bariatric surgery procedures

\begin{tabular}{|c|c|c|c|}
\hline $\begin{array}{l}\text { Type of } \\
\text { surgery }\end{array}$ & Adjustable gastric banding & Sleeve gastrectomy & Roux-en-Y gastric bypass (RYGB) \\
\hline \multirow[t]{3}{*}{$\begin{array}{l}\text { Mechanism for } \\
\text { weight loss }\end{array}$} & \multirow[t]{3}{*}{$\begin{array}{l}\text { Restricts food intake (Buchwald, et } \\
\text { al., 2009; Obesity Surgery Society } \\
\text { of Australia and New Zealand, } \\
\text { 2017) }\end{array}$} & Restricts food intake & Restricts food intake \\
\hline & & \multirow[t]{2}{*}{$\begin{array}{l}\text { Suppression of hunger through changes } \\
\text { to hormones (Obesity Surgery Society of } \\
\text { Australia and New Zealand, 2017) }\end{array}$} & $\begin{array}{l}\text { Suppression of hunger through } \\
\text { changes to hormones }\end{array}$ \\
\hline & & & $\begin{array}{l}\text { Reduces absorption of nutrient and } \\
\text { delays digestion (Buchwald, et al., } \\
\text { 2009; Obesity Surgery Society of } \\
\text { Australia and New Zealand, 2017) }\end{array}$ \\
\hline Procedure & $\begin{array}{l}\text { A band is placed around the upper } \\
\text { stomach to create a small pouch, } \\
\text { this can be adjusted through } \\
\text { increasing or decreasing fluid in the } \\
\text { band (Obesity Surgery Society of } \\
\text { Australia and New Zealand, 2017) }\end{array}$ & $\begin{array}{l}\text { Surgical removal of the outer part of the } \\
\text { stomach and reshaping of the stomach to } \\
\text { a sleeve shape occurs. This reduces the } \\
\text { volume to approximately } 100-150 \mathrm{~mL} \\
\text { (from 2L) (Obesity Surgery Society of } \\
\text { Australia and New Zealand, 2017) }\end{array}$ & $\begin{array}{l}\text { The procedure causes food to } \\
\text { bypass the stomach directly to a } \\
\text { gastric pouch with a volume of } \\
\text { approximately } 15 \mathrm{~mL} \text { then proceeds to } \\
\text { the jejunum (Obesity Surgery Society } \\
\text { of Australia and New Zealand, 2017) }\end{array}$ \\
\hline $\begin{array}{l}\text { Follow up } \\
\text { required }\end{array}$ & $\begin{array}{l}1 \text { month post-surgery Minimum } \\
\text { every } 3 \text { months for first year until } \\
\text { adequate clinical weight loss } \\
\text { achieved Thereafter minimum of } \\
\text { annually Repeated band adjustments } \\
\text { as required (Fried, et al., 2013) }\end{array}$ & $\begin{array}{l}1 \text { month post-surgery Minimum every } \\
3 \text { months for the first year (Fried, et al., } \\
2013 \text { ). }\end{array}$ & $\begin{array}{l}1 \text { month post-surgery Minimum } \\
\text { every } 3 \text { months for the first year. } \\
\text { Minimum every } 6 \text { months for second } \\
\text { year Annually thereafter (Fried, et } \\
\text { al., 2013) }\end{array}$ \\
\hline $\begin{array}{l}\text { Remission of } \\
\text { type } 2 \text { diabetes }\end{array}$ & 20\% (Pham, et al., 2014) & $62.5 \%$ (Pham, et al., 2014) & $52 \%$ (Pham, et al., 2014) \\
\hline Weight loss & $\begin{array}{l}\text { Median } 37 \% \text { excess weight loss } \\
1 \text { year post-surgery. Median } 3 \\
\text { years post-surgery } 40 \% \text { patients } \\
\text { maintained }>50 \% \text { excess weight loss } \\
\text { (Coleman, et al., 2014) }\end{array}$ & $\begin{array}{l}\text { Median } 56 \% \text { excess weight loss } 1 \text { year } \\
\text { post-surgery Median } 3 \text { years post-surgery } \\
46 \% \text { patients maintained }>50 \% \text { excess } \\
\text { weight loss (Coleman, et al., } 2014 \text { ) }\end{array}$ & $\begin{array}{l}\text { Median } 66.5 \% \text { excess weight loss } \\
1 \text { year post-surgery Median } 3 \\
\text { years post-surgery } 65 \% \text { patients } \\
\text { maintained }>50 \% \text { excess weight loss } \\
\text { (Coleman, et al., 2014) }\end{array}$ \\
\hline Complications & $\begin{array}{l}\text { Meta-analysis of RCTs indicates } \\
\text { complication rates of } 13 \% \text { (Chang, } \\
\text { et al., 2014) }\end{array}$ & $\begin{array}{l}\text { Meta-analysis of RCTs indicates } \\
\text { complication rates of } 13 \% \text { (Chang, et al., } \\
\text { 2014) }\end{array}$ & $\begin{array}{l}\text { Meta-analysis of RCTs indicates } \\
\text { complication rates of } 21 \% \text { (Chang, et } \\
\text { al., 2014) }\end{array}$ \\
\hline
\end{tabular}




\section{Comparison of interventions}

A systematic review and meta-analysis by Müller Stich, et al. ${ }^{27}$ determined that surgical management for obese individuals with T2DM was more effective in lowering glycated haemoglobin A1c, improving glycaemic control and had higher rates of T2DM remission than medical management in nonseverely obese individuals in the short term (12-36 months). A systematic review and meta-analysis of the long term ( 3 years) effectiveness of bariatric surgery compared to non-surgical intervention established that bariatric surgery was superior in eliciting: weight loss, remission of diabetes, larger reductions in glycated haemoglobin A1c, and decreased systolic pressure. ${ }^{28}$ Furthermore a 5 year controlled trial also confirmed the superiority of surgical intervention over medical management for obesity in T2DM, espousing that over $80 \%$ of individuals whom underwent bariatric surgery maintained a glycated haemoglobin A1c of $<7 \%$ with no or few antidiabetic medications Mingrone, et al. ${ }^{29}$ Table 4 demonstrates further associated benefits and complications of bariatric surgery and a comparison of lifestyle with pharmaceutical intervention versus bariatric surgery; the evidence confirms that surgical intervention is superior to pharmalogical intervention for obesity in T2DM. ${ }^{30-32}$

Table 4 Bariatric surgery clinical trials

\begin{tabular}{|c|c|c|c|}
\hline Study & Weight loss & Complications & Benefits \\
\hline $\begin{array}{l}\text { Swedish Obesity } \\
\text { Subjects trial (SOS) } \\
\text { (Sjostrom, 2013) }\end{array}$ & $\begin{array}{l}\text { Mean weight loss } \\
\text { below baseline: } \\
\text { 1-2 years RYGB } \\
32 \pm 8 \% \text { Gastric } \\
\text { banding } 20 \pm 10 \%\end{array}$ & $\begin{array}{l}\text { Over first } 3 \text { months: } 0.25 \% \text { deaths } \\
\text { in intervention group compared to } \\
0.1 \% \text { in control group One or more } \\
\text { nonfatal complication in } 14.5 \% \\
\text { of bariatric intervention group; } \\
2.9 \% \text { of these patients required } \\
\text { reoperation. }\end{array}$ & $\begin{array}{l}30 \% \text { risk reduction in mortality after } 13 \text { years. } 72 \% \\
\text { remission in T2DM after } 2 \text { years Long-term reduced } \\
\text { macrovascular complications post-surgery Patient reported } \\
\text { reductions in sleep apnoea from } 23 \% \text { pre-surgery to } 8 \% 2 \\
\text { years post-surgery Increased physical activity at } 2 \text { and } 10 \\
\text { year follow-up Improved quality of life at } 10 \text { year follow-up }\end{array}$ \\
\hline
\end{tabular}

After 10 years RYGB $25 \pm 11 \%$ Gastric banding $14 \pm 14 \%$

15 years RYGB $27 \pm 12 \%$ Gastric banding $13 \pm 14 \%$

The Diabetes Surgery Study (Ikramuddin, et al., 2013). Comparison of efficacy of RYGB versus intensive lifestyle with pharmacotherapy

Study

Swedish Obesity Subjects trial (SOS) (Sjostrom, 2013)
Mean weight loss below baseline: 1-2 years RYGB $32 \pm 8 \%$ Gastric banding $20 \pm 10 \%$
$50 \%$ and $55 \%$ more RYGB participants suffered serious adverse events and non-serious adverse events respectively compared to participants from the lifestyle pharmacotherapy group.

Complications

Over first 3 months: $0.25 \%$ deaths in intervention group compared to $0.1 \%$ in control group One or more nonfatal complication in $14.5 \%$ of bariatric intervention group; $2.9 \%$ of these patients required reoperation.

After 10 years RYGB $25 \pm 11 \%$ Gastric banding $14 \pm 14 \%$

15 years RYGB $27 \pm 12 \%$ Gastric banding $13 \pm 14 \%$

The Diabetes Surgery Study (Ikramuddin, et al., 2013). Comparison of efficacy of RYGB versus intensive lifestyle with pharmacotherapy
$50 \%$ and $55 \%$ more RYGB

$26.1 \%$ loss of initial body weight with RYGB participants suffered serious adverse events and non-serious adverse events respectively compared to participants from the lifestyle pharmacotherapy group.
$75 \%$ of RYGB participants achieved A1c $<7 \%$ compared to $32 \%$ in the lifestyle pharmacotherapy group

Benefits

$30 \%$ risk reduction in mortality after 13 years. $72 \%$ remission in T2DM after 2 years Long-term reduced macrovascular complications post-surgery Patient reported reductions in sleep apnoea from $23 \%$ pre-surgery to $8 \% 2$ years post-surgery Increased physical activity at 2 and 10 year follow-up Improved quality of life at 10 year follow-up
$75 \%$ of RYGB participants achieved A1c $<7 \%$ compared to $32 \%$ in the lifestyle pharmacotherapy group 


\section{Conclusion}

Diabesity detrimentally affects quality of life, life expectancy and places significant demands on healthcare resources. If T2DM and obesity cannot be prevented then efficacious and cost effective management and interventions must be implemented. There is a significant clinical evidence to suggest that pharmaceutical and surgical interventions can be effective for combating obesity in $\mathrm{T} 2 \mathrm{DM}$ and thus improving glycaemic control and reducing related co-morbidities. The large scale clinical trials of both surgical and pharmaceutical interventions need to be replicable in the real world and, as of yet, despite the promising results within trials many pharmaceutical interventions fall short. However meta-analysis of surgical interventions has shown long term success in maintaining weight loss and remission of T2DM. The feasibility of health systems to offer bariatric surgery to all those in need is a huge question and more effective pharmacological interventions should be sought through research and development. Nevertheless, optimum diet and active lifestyle should be promoted to prevent obesity in the first instance as an effective strategy.

\section{Acknowledgements}

None.

\section{Conflict of interest}

The author declares no conflict of interest.

\section{References}

1. Ribaric G, Buchwald JN, McGlennon TW. Diabetes and weight in comparative studies of bariatric surgery $\mathrm{V}_{\mathrm{s}}$ conventional medical therapy: a systematic review and meta-analysis. Obes Surg Volume. 2014;24(3):437455 .

2. Obesity: Preventing and Managing the Global Epidemic-World Health Organization; 2000. p. 1-253.

3. Ladenheim EE. Liraglutide and obesity: a review of the data so far. Drug Des Devel Ther. 2015;9:1867-1875.

4. Clinical Practice Guidelines for the Management of Overweight and Obesity in Adults. Adolescents and Children in Australia, Melbourne, Australia: National health and medical research council; 2013. p. 1-234.

5. Al Goblan AS, Al Alfi MA, Khan MZ. Mechanism linking diabetes mellitus and obesity. Diabetes Metab Syndr Obes. 2014;7:587-591.

6. Van Gaal L, Scheen A. Weight management in type 2 diabetes: current and emerging approaches to treatment. Diabetes Care. 2015;38(6):1161-1172.

7. American diabetes association. Obesity management for the management of type 2 diabetes. Diabetes Care. 2016;39(1):S47-51.

8. Goswami G, Shinkazh N, Davis N. Optimal pharmacologic treatment strategies in obesity and type 2 diabetes. J Clin Med. 2014; 3(2):595-613.

9. Thévenod F. Diabetes and Cancer. Epidemiological evidence and molecular links. In: Masur K, et al. editors. Pathophysiology of diabetes mellitus type 2: Roles of obesity, Insulin resistance and $\beta$-cell dysfunction. Germany: Karger Publishers; 2008. p. 1-18.

10. Scottish intercollegiate guidelines network. Management of Obesity A National Clinical Guideline 115. UK: SIGN; 2010. p.1-96.

11. Sjöström L. Review of the key results from the swedish obese subjects (SOS) trial-a prospective controlled intervention study of bariatric surgery. J Intern Med. 2013;273(3):219-234.
12. Pham S, Gancel A, Scotte M, et al. comparison of the effectiveness of four bariatric surgery procedures in obese patients with type 2 diabetes: a retrospective Study. J Obesity. 2014. p. 1-7.

13. Yanovski SZ, Yanovski JA. Long-term drug treatment for obesity: a systematic and clinical review. JAMA. 2014;311(1):74-86.

14. Umpierrez GE, Pantalone KM, Kwan AY, et al. Relationship between weight change and glycaemic control in patients with type 2 diabetes receiving once-weekly dulaglutide treatment. Diabetes Obes Metab. 2016;18(6):615-622.

15. Ikramuddin S, Korner J, Lee WJ, et al. Roux-en-Y gastric bypass $\mathrm{v}_{\mathrm{s}}$ Intensive medical management for the control of type 2 diabetes, hypertension, and hyperlipidemia. the diabetes surgery study randomized clinical trial. JAMA. 2013;309(21):224-2249.

16. Dunkley AJ, Bodicoat DH, Greaves CJ, et al. Diabetes prevention in the real world: effectiveness of pragmatic lifestyle interventions for the prevention of type 2 diabetes and of the impact of adherence to guideline recommendations a systematic review and meta-analysis. Diabetes Care. 2014;37(4):922-933.

17. Amin T, Mercer JG. Hunger and satiety mechanisms and their potential exploitation in the regulation of food intake. Curr Obes Rep. 2016;5(1):106-112.

18. Obesity Surgery Society of Australia and New Zealand; 2017.

19. NICE. Obesity: identification, assessment and management (CG189). National Institute for Health and Care Excellence, UK; 2014. p. 1-64.

20. Busetto L. Timing of bariatric surgery in people with obesity and diabetes. Ann Transl Med. 2015;3(7):94.

21. Shannon C, Gervasoni A, Williams T. The bariatric surgery patient. Aust Fam Physician. 2013;42(8):547-552.

22. Picot J, Jones J, Colquitt JL, et al. The clinical effectiveness and costeffectiveness of bariatric (weight loss) surgery for obesity: a systematic review and economic evaluation. Health Technol Assess. 2009;13(41):1-6.

23. Tang Q, Sun Z, Zhang N, et al. Cost-effectiveness of bariatric surgery for type 2 diabetes mellitus. a randomized controlled trial in China. Medicine (Baltimore). 2016;95(20):e3522.

24. Dirksen C, Jørgensen NB, Bojsen-Møller KN, et al. Mechanisms of improved glycaemic control after roux-en-Y gastric bypass. Diabetologia. 2012;55(7):1890-1901.

25. Thomas F, Smith GC, Lu J, et al. Differential acute impacts of sleeve gastrectomy, roux-en-Y gastric bypass surgery and matched caloric restriction diet on insulin secretion, insulin effectiveness and nonesterified fatty acid levels among patients with Type 2 diabetes. Obes Surg. 2016;26(8):1924-1931.

26. Buchwald H, Estok R, Fahrbach K, et al. Weight and type 2 diabetes after bariatric surgery: systematic review and meta-analysis. Am J Med. 2009;122(3):248-256.

27. Müller Stich BP, Senft JD, Warschkow R, et al. Surgical Versus medical treatment of type 2 diabetes mellitus in nonseverely obese patients: a systematic review and meta-Analysis. Ann Surg. 2015;261(3):421-429.

28. Cheng J, Gao J, Shuai X, et al. The Comprehensive Summary of Surgical Versus Non-Surgical Treatment for Obesity: a Systematic Review and Meta-Analysis of Randomized Controlled Trials. Oncotarget. 2016;7(26):39216-39230.

29. Mingrone G, Panunzi S, Gaetano AD, et al. Bariatric-metabolic surgery Vs conventional medical treatment in obese patients with type 2 diabetes: 5 year follow-up of an open-label, single-centre, randomised controlled trial. Lancet. 2015;386:964-973. 
30. Chang SH, Stoll CR, Song J, et al. Bariatric surgery: an updated systematic review and meta-analysis, 2003-2012. JAMA Surg. 2014;149(3):275-287.

31. Coleman KJ, Huang YC, Hendee F, et al. Three-year weight outcomes from a bariatric surgery registry in a large integrated healthcare system. Surg Obes Relat Dis. 2014;10(3):396-404
32. Fried M, Yumuk V, Oppert JM, et al. Interdisciplinary European guidelines on metabolic and bariatric surgery. Obes Surg. 2013;24(1):42-55. 